Wright State University

CORE Scholar

6-1-2005

\title{
Role of Near-Surface States in Ohmic-Schottky Conversion of Au Contacts to $\mathrm{ZnO}$
}

\author{
H. L. Mosbacker \\ Y. M. Strzhemechny \\ B. D. White \\ P. E. Smith \\ David C. Look \\ Wright State University - Main Campus, david.look@wright.edu
}

See next page for additional authors

Follow this and additional works at: https://corescholar.libraries.wright.edu/physics

Part of the Physics Commons

\section{Repository Citation}

Mosbacker, H. L., Strzhemechny, Y. M., White, B. D., Smith, P. E., Look, D. C., Reynolds, D. C., Litton, C. W., \& Brillson, L. J. (2005). Role of Near-Surface States in Ohmic-Schottky Conversion of Au Contacts to ZnO. Applied Physics Letters, 87 (1), 12102.

https://corescholar.libraries.wright.edu/physics/90

This Article is brought to you for free and open access by the Physics at CORE Scholar. It has been accepted for inclusion in Physics Faculty Publications by an authorized administrator of CORE Scholar. For more information, please contact library-corescholar@wright.edu. 


\section{Authors}

H. L. Mosbacker, Y. M. Strzhemechny, B. D. White, P. E. Smith, David C. Look, D. C. Reynolds, C. W. Litton, and L. J. Brillson

This article is available at CORE Scholar: https://corescholar.libraries.wright.edu/physics/90 


\title{
Role of near-surface states in ohmic-Schottky conversion of Au contacts to $\mathrm{ZnO}$
}

\author{
H. L. Mosbacker, ${ }^{a), b)}$ Y. M. Strzhemechny, and B. D. White \\ Department of Electrical and Computer Engineering, The Ohio State University, Columbus, Ohio 43210 \\ P. E. Smith \\ Department of Physics, The Ohio State University, Columbus, Ohio 43210 \\ D. C. Look, ${ }^{\text {c) }}$ D. C. Reynolds, and C. W. Litton \\ Air Force Research Laboratory, AFRL/MLPS, Wright-Patterson Air Force Base, Ohio 45435 \\ L. J. Brillson ${ }^{\text {b),d) }}$ \\ Department of Electrical and Computer Engineering, The Ohio State University, Columbus, Ohio 43210
}

(Received 20 April 2005; accepted 23 May 2005; published online 27 June 2005)

\begin{abstract}
A conversion from ohmic to rectifying behavior is observed for Au contacts on atomically ordered polar $\mathrm{ZnO}$ surfaces following remote, room-temperature oxygen plasma treatment. This transition is accompanied by reduction of the "green" deep level cathodoluminescence emission, suppression of the hydrogen donor-bound exciton photoluminescence and a $\sim 0.75 \mathrm{eV}$ increase in $n$-type band bending observed via $\mathrm{x}$-ray photoemission. These results demonstrate that the contact type conversion involves more than one mechanism, specifically, removal of the adsorbate-induced accumulation layer plus lowered tunneling due to reduction of near-surface donor density and defect-assisted hopping transport. (C) 2005 American Institute of Physics. [DOI: 10.1063/1.1984089]
\end{abstract}

Recent advances in crystal growth allow bulk production of high-quality single crystals of semiconducting $\mathrm{ZnO}$ with high potential for optoelectronic, spintronic, and hightemperature, high-power microelectronic applications. ${ }^{1}$ While considerable progress has been made in understanding the semiconducting properties of $\mathrm{ZnO}$, many questions remain open on the nature of its transport phenomena. In particular, fabrication of stable and rectifying metal contacts to $\mathrm{ZnO}$ remains a challenge despite numerous recent investigations. ${ }^{1-12}$ A number of studies have addressed various possible fundamental mechanisms affecting Schottky barrier (SB) performance in $\mathrm{ZnO},{ }^{1,5,9-13}$ but none have considered the role of both the surface and subsurface. Thus, while several studies have proposed that surface morphology, hydroxide $(\mathrm{OH})$, and carbon surface contamination play a dominant role, none have considered the role of subsurface defects and impurities that could alter local carrier concentrations, depletion widths, and tunneling. Here, we address all of these mechanisms using a combination of an ultrahigh vacuum (UHV) surface and subsurface characterization and processing techniques.

Single-crystal $\mathrm{ZnO}$ samples were grown by chemical vapor transport at Eagle-Picher Inc. (E-P) and polished on both the (0001) Zn and (0001) O faces. We used samples of two grades: "High-quality" material with relatively smooth surfaces [root-mean-square (rms) roughness $\sim 0.1 \mathrm{~nm}$ ] and low "green" defect (GD) luminescence versus "lowerquality" $\mathrm{ZnO}$ with rougher surfaces ( $\mathrm{rms}$ roughness $\sim 5 \mathrm{~nm}$ ), micropits, and approximately two times higher GD lumines-

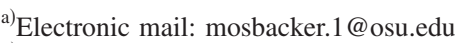

b) Also at: Department of Physics, The Ohio State University, Columbus, Ohio 43210.

${ }^{c)}$ Also at: Semiconductor Research Center, Wright State University, Dayton, Ohio 45435

d) Also at: Center for Materials Research, The Ohio State University, Columbus, Ohio 43210.
}

cence. We also used single-crystal $\mathrm{ZnO}$ samples grown by a pressurized melt growth process at Cermet Inc. with a rms roughness $\sim 2.0 \mathrm{~nm}$ and a relatively high GD luminescence. All samples were chemically cleaned with a 5 min ultrasonic bath in acetone, toluene, dimethylsulfuoxide, methanol, and deionized water, and then blown dry with nitrogen gas. $\mathrm{Au}$ circular contacts $\sim 0.5 \mathrm{~mm}$ in diameter were deposited in a UHV chamber by thermal evaporation from a tungsten filament through a shadow mask for both plasma-exposed and unexposed samples. $\mathrm{ZnO}$ crystals at room temperature were processed in situ with remote $20 \%$ oxygen- $80 \%$ helium mix plasma inductively produced by an rf generator operating at $30 \mathrm{~W}$, with a pressure of 10 mTorr. The remote oxygen plasma permitted independent control of temperature and pressure. Both plasma-exposed and unexposed samples were characterized in situ with cathodoluminesence (CL), x-ray photoelectron spectroscopy (XPS), and low-energy electron diffraction (LEED). Ex situ atomic force microscopy (AFM), low temperature photoluminescence (LT PL), as well as current-voltage $(I-V)$, and capacitance-voltage $(C-V)$ measurements were also performed before and after plasma exposure. More detailed descriptions of the experimental setups appear elsewhere. ${ }^{14}$

$\mathrm{All} \mathrm{Au}-\mathrm{ZnO}$ contacts formed without prior oxygen treatment exhibited ohmic transport characteristics. We found that $\mathrm{ZnO}$ exposure to the remote $\mathrm{O} / \mathrm{He}$ plasma for $1 \mathrm{~h}$ or more consistently changes $\mathrm{Au}$ contacts on $\mathrm{ZnO}$ from ohmic to rectifying regardless of surface polarity and material quality. Various oxidation treatments reported previously ${ }^{1,9,11,12}$ also report similar effects but attribute them to widely different mechanisms. Figure 1 illustrates this ohmic-Schottky conversion for different material grades and polarity. Corresponding $C-V$ experiments (not shown) agreed with the $I-V$ SB heights of $0.42-0.5 \mathrm{eV}$, once the image force lowering was taken into account. Figure 1(b) shows that gradual ohmic-to-Schottky-type $I-V$ changes take place between 0 , 


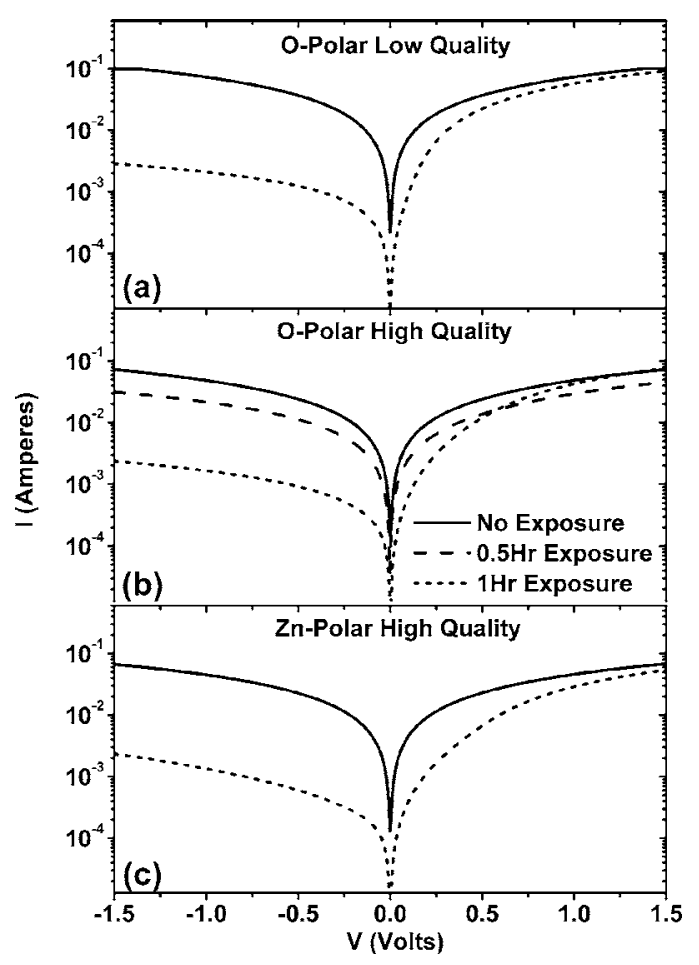

FIG. 1. I-V characteristics for remote plasma-exposed and unexposed E-P samples. (a) $1 \mathrm{~h}$ exposure of the $(000 \overline{1})$ surface produces a SB of $0.5 \mathrm{eV}$ with an ideality $\sim 2$ for the lower grade material. (b) The same transition occurs for a $1 \mathrm{~h}$ exposed sample of higher quality with a calculated SB height of $0.42 \mathrm{eV}$ and ideality $>8$, however, a $30 \mathrm{~min}$ exposure indicates an ohmic behavior. (c) Higher-quality (0001) surfaces change from ohmic to rectifying after $1 \mathrm{~h}$ plasma treatment with $0.5 \mathrm{eV} \mathrm{SB}$ and $\sim 5$ ideality.

30, and 60 min room-temperature plasma exposure. Cermet $\mathrm{ZnO} I-V$ changes (not shown) also vary within this exposure range, ranging from ohmic ( $0 \mathrm{~min})$ to $\sim 0.4 \mathrm{eV} \mathrm{SB}$ and high ideality $n=5(30 \mathrm{~min})$ to $0.5 \mathrm{eV} \mathrm{SB}$ with $n=2(60 \mathrm{~min})$. The high ideality values calculated indicate that field emission and recombination contribute to the measured current transport. Both direct and trap-assisted tunneling can occur and are affected by the carrier concentration and barrier shape as well as the concentration of tunneling-mediating defects.

XPS results are given in Fig. 2 for the unexposed and a 60 min plasma-exposed sample. The $\mathrm{OH} /$ lattice oxygen ratio decreases from $\sim 2.9$ before exposure to $\sim 0.3$ (cylindrical mirror analyzer precision $\pm 10-20 \%$ ) after exposure, indicating almost complete removal of $\mathrm{OH}$ from the surface [Fig. 2(a)]. Previous work ${ }^{9,11}$ suggested $\mathrm{OH}$ contamination on polar $\mathrm{ZnO}$ surfaces as the primary factor degrading rectifying contact performance: High surface $\mathrm{OH}$ can create a surface conductive accumulation layer that oxygen plasma removes, lowering the Fermi level $E_{F}$ into the band gap, resulting in a rectifying contact. Our posttreatment rigid $\mathrm{O} 1 s$ and $\mathrm{Zn} 2 p$ core-level shifts [Figs. 2(a) and 2(b)] of $0.74 \pm 0.05 \mathrm{eV}$ toward lower binding energy indicate $n$-type (upward) band bending, consistent with accumulation layer removal and similar to previous results. ${ }^{9,11}$ The $\mathrm{O} / \mathrm{He}$ plasma also produces an apparent increase in the oxygen near-surface composition, increasing the $\mathrm{O} / \mathrm{Zn}$ ratio from 1.04 to 1.15 after plasma exposure. Since oxygen deficiency-related defects within the band gap could provide a mechanism for charge hopping, reduction of this deficiency would decrease possible tunneling through the SB. Figure 2(c) shows a removal of the $\mathrm{C} 1 \mathrm{~s}$ peak, consistent with previous studies. ${ }^{9,11} \mathrm{~A}$

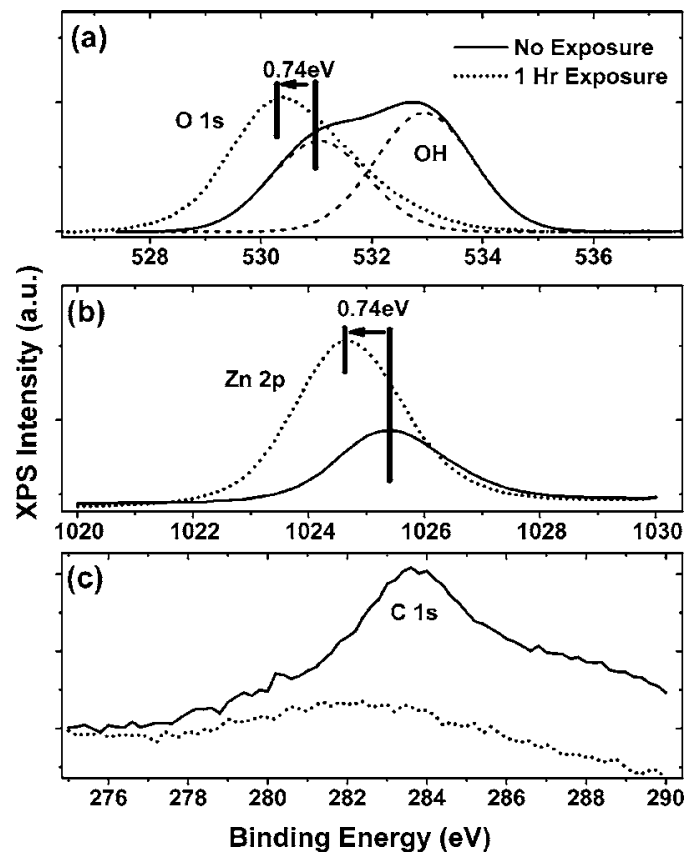

FIG. 2. XPS results before and after $1 \mathrm{~h} 20 \% \mathrm{O}_{2} / 80 \%$ He plasma treatment (low grade E-P sample). (a) Plasma treatment removes the (deconvolved) $\mathrm{OH}$ peak and shifts the $\mathrm{O} 1 s$ peak rigidly by $0.74 \mathrm{eV}$, as well as the $\mathrm{Zn} 2 p$ peak in (b), indicating $n$-type band bending. (c) The $\mathrm{C} 1 s$ peak disappears after plasma treatment, leaving only a $\mathrm{Zn}$ Auger shoulder, indicating removal of adsorbed carbon.

30 min plasma treatment of Cermet $\mathrm{ZnO}$ polar surfaces also results in $\mathrm{C}$ removal, negligible $\mathrm{OH}$, and $>0.5 \mathrm{eV} n$-type band bending, indicating the removal of any adsorbateinduced surface accumulation. However, the continued change in ohmic-to-Schottky behavior beyond this $30 \mathrm{~min}$ exposure demonstrates that more than $\mathrm{C}$ and $\mathrm{OH}$ adsorbates are involved, implying that subsurface electronic changes also play a role in the SB formation.

In situ LEED experiments (not shown) revealed a slight improvement of the hexagonal pattern subsequent to plasma treatment and adsorbate removal, consistent with clean atomically ordered surfaces. AFM measurements (not shown) indicated insignificant damage produced by the remote plasma. Evidently, this did not substantially affect the transport properties of the contacts.

Depth-resolved CL spectra for both unexposed and exposed $(000 \overline{1}) \mathrm{ZnO}$ in Fig. 3 indicate electronic changes below the free surface. Typical spectra include a near-band edge (NBE) $3.3 \mathrm{eV}$ emission and a broad $2.5 \mathrm{eV}$ GD emission often attributed to oxygen deficiency. ${ }^{15}$ Figure 3 shows that GD emission is dominant at the surface. This behavior is independent of the surface polarity and material quality. The ratio of the integrated green versus NBE intensities increases by a factor of 2 at the surface and levels off to a constant value into the bulk at $\sim 25 \mathrm{~nm}$. After $1 \mathrm{~h}$ of plasma exposure, the sample exhibits a 50\% decrease in GD emission intensity, suggesting defect passivation or removal. Both high and low grade $\mathrm{ZnO}$ exhibit this effect. However, the higher-quality $\mathrm{ZnO}$ required longer exposure time to achieve similar $50 \%$ GD intensity reduction (e.g., $30 \mathrm{~min}$ plasma treatment produced only insignificant changes). If one assumes that the suppression of the GD emission is associated with the reduction in oxygen deficiency (independently confirmed by our 


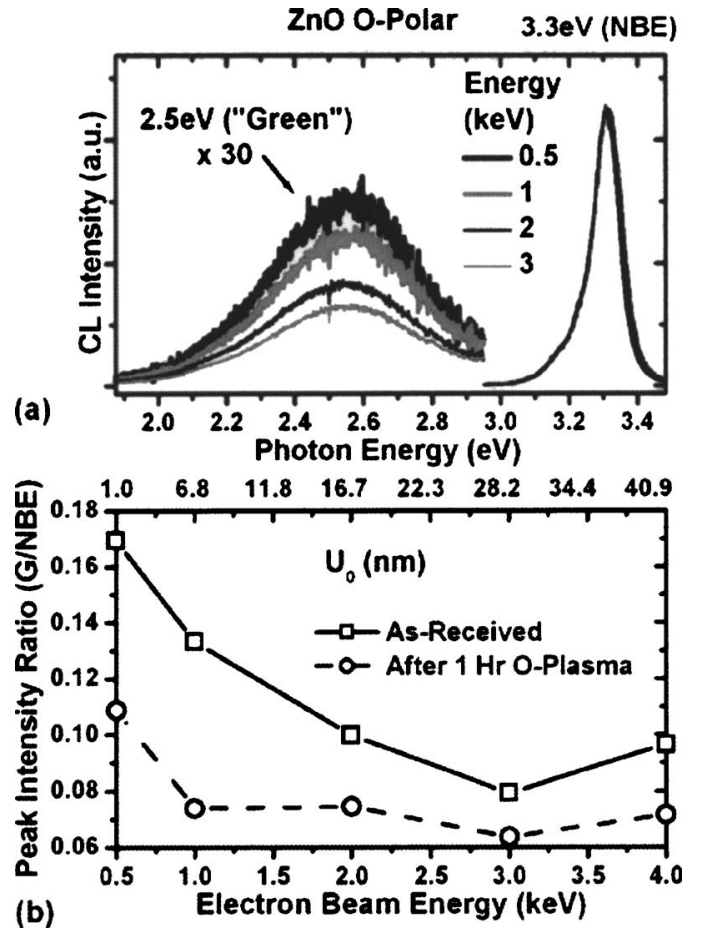

FIG. 3. CL spectra for treated and untreated E-P samples of a lower grade. (a) Relative CL intensity for the $2.5 \mathrm{eV}$ (green) emission, often attributed to oxygen vacancies, decreases with increasing electron-beam energy. All spectra are normalized to NBE. (b) The integrated peak intensity ratio (GD/ NBE) vs electron-beam energy indicates a factor of 2 increase in GD defect concentration within $25 \mathrm{~nm}$ of the surface. After a $1 \mathrm{~h}$ exposure, the intensity decreases by $50 \%$, indicating GD partial removal or passivation.

XPS measurement), then we have an indication of removal of potential tunneling-promoting defects.

LT PL spectra were acquired before and after $1 \mathrm{~h}$ of exposure to remote plasma (Fig. 4). The intensity of the peak with the photon energy of $\sim 3.363 \mathrm{eV}$ (commonly designated as $I_{4}$ ) is dramatically reduced after the plasma treatment. This reduction occurs for both polar faces, regardless of sample grade. There is strong evidence in favor of attributing the $I_{4}$ emission to a neutral hydrogen donor bound exciton, ${ }^{16}$ recently demonstrated both optically and electronically. ${ }^{17}$

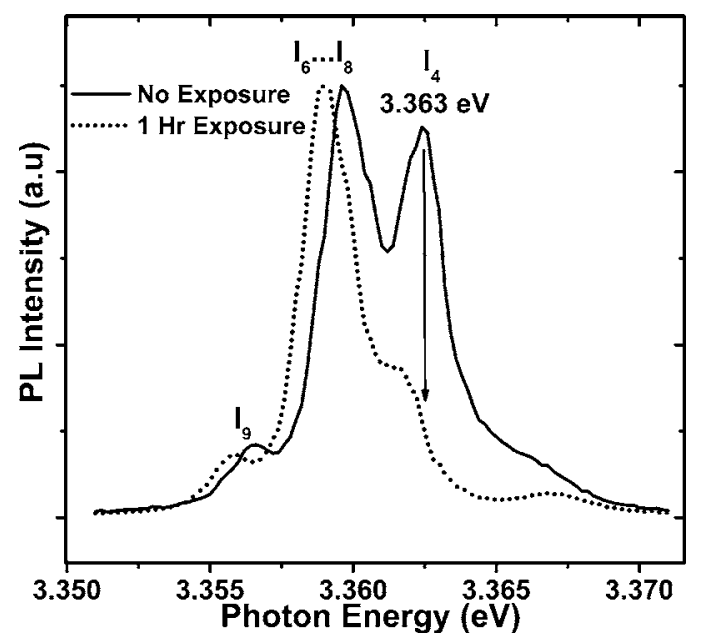

FIG. 4. Photoluminescence spectra taken at $9 \mathrm{~K}$ in the bound exciton region for the $(000 \overline{1})$ polar $\mathrm{ZnO}$ high grade E-P surface. The $I_{4}$ line attributed to hydrogen as a shallow donor in $\mathrm{ZnO}$ is significantly reduced after a $1 \mathrm{~h}$ plasma exposure.
The reduction of the $I_{4}$ peak by plasma treatment indicates removal of hydrogen attributed to this peak. Hydrogen may play an important role at the $\mathrm{Au} / \mathrm{ZnO}$ interface as a shallow donor, ${ }^{18}$ narrowing the depletion region or even forming an accumulation layer, both acting to lower the effective SB. Thus, increased donor concentrations of $\sim 2 \times 10^{18} \mathrm{~cm}^{-3}$ correspond to depletion widths of only $100 \AA$ or less.

In summary, extended ( $1 \mathrm{~h}$ or longer) room-temperature surface treatment of $\mathrm{ZnO}$ with $20 \%$ oxygen- $80 \%$ helium plasma consistently transforms ohmic Au contacts to $\mathrm{ZnO}$ into rectifying barriers. Au- $\mathrm{ZnO}$ ohmic contacts result not only from an $\mathrm{OH}$-induced accumulation but also tunneling due to increased donor concentrations that decrease the depletion width as well as hopping transport via deep levels.

The authors gratefully acknowledge support from the Office of Naval Research (Colin Wood), the Department of Energy Grant No. DE-FG02-97ER45666 (depth-resolved measurements) (Jane Zhu), and the National Science Foundation (Verne Hess). Opinions, interpretations, conclusions, and recommendations are those of the authors and not necessarily endorsed by the United States Air Force.

${ }^{1}$ S. J. Pearton, D. P. Norton, K. Ip, Y. W. Heo, and T. Steiner, Prog. Mater. Sci. 50, 293 (2005), and references therein.

${ }^{2}$ S. Liang, H. Sheng, Y. Liu, Z. Huo, Y. Lu, and H. Shen, J. Cryst. Growth 225, 110 (2000).

${ }^{3}$ A. Salomon, D. Berkovich, and D. Cahen, Appl. Phys. Lett. 82, 1051 (2003).

${ }^{4}$ W. I. Park, G.-C. Yi, J.-W. Kim, and S. M. Park, Appl. Phys. Lett. 82, 4358 (2003).

${ }^{5}$ H. von Wenckstern, E. M. Kaidashev, M. Lorenz, H. Hochmuth, G. Biehne, J. Lenzner, V. Gottschalch, R. Pickenhain, and M. Grundmann, Appl. Phys. Lett. 84, 79 (2004).

${ }^{6}$ K. Keem, H. Kim, G.-T. Kim, J. S. Lee, B. Min, K. Cho, M.-Y. Sung, and S. Kim, Appl. Phys. Lett. 84, 4376 (2004).

${ }^{7}$ S. Kim, B. S. Kang, F. Ren, K. Ip, Y. W. Heo, D. P. Norton, and S. J. Pearton, Appl. Phys. Lett. 84, 1698 (2004).

${ }^{8}$ K. Ip, Y. W. Heo, K. H. Baik, D. P. Norton, S. J. Pearton, S. Kim, J. R. LaRoche, and F. Ren, Appl. Phys. Lett. 84, 2835 (2004).

${ }^{9}$ K. Ip, B. P. Gila, A. H. Onstine, E. S. Lambers, Y. W. Heo, K. H. Baik, D. P. Norton, and S. J. Pearton, Appl. Phys. Lett. 84, 5133 (2004).

${ }^{10}$ H. Sheng, S. Muthukumar, N. W. Emanetoglu, and Y. Lu, Appl. Phys. Lett. 80, 2132 (2002).

${ }^{11}$ B. J. Coppa, R. F. Davis, and R. J. Nemanich, Appl. Phys. Lett. 82, 400 (2003); B. J. Coppa, C. C. Fulton, P. J. Hartlieb, R. F. Davis, B. J. Rodriguez, B. J. Shields, and R. J. Nemanich, J. Appl. Phys. 95, 5856 (2004).

${ }^{12}$ S.-H. Kim, H.-K. Kim, and T.-Y. Seong, Appl. Phys. Lett. 86, 112101 (2005).

${ }^{13}$ H.-K. Kim, K.-K. Kim, A.-J. Park, T.-Y. Seong, and I. Adesida, J. Appl. Phys. 94, 4225 (2003).

${ }^{14}$ Y. Shapira, C. F. Brucker, and L. J. Brillson, Thin Solid Films 135, 203 (1986); L. J. Brillson, T. M. Levin, G. H. Jessen, and F. A. Ponce, Appl. Phys. Lett. 75, 3835 (1999); S. Tumakha, S. H. Goss, L. J. Brillson, and R. S. Okojie, J. Vac. Sci. Technol. B 23, 594 (2005).

${ }^{15}$ F. H. Leiter, H. R. Alves, A. Hofstaetter, D. M. Hofmann, and B. K. Meyer, Phys. Status Solidi B 226, R4 (2001); F. Leiter, H. Zhou, F. Henecker, A. Hofstaetter, D. M. Hofmann, and B. K. Meyer, Physica B 308, 908 (2001); F. Leiter, H. Alves, D. Pfisterer N. G. Romanov, D. M. Hofmann, and B. K. Meyer, ibid. 340, 201 (2003).

${ }^{16}$ A. V. Rodina, M. Strassburg, M. Dworzak, U. Haboeck, A. Hoffmann, A. Zeuner, H. R. Alves, D. M. Hofmann, and B. K. Meyer, Phys. Rev. B 69, 125206 (2004)

${ }^{17}$ Y. M. Strzhemechny, H. L. Mosbacker, D. C. Look, D. C. Reynolds, C. W. Litton, N. Y. Garces, N. C. Giles, L. E. Halliburton, S. Niki, and L. J. Brillson, Appl. Phys. Lett. 84, 2545 (2004).

${ }^{18}$ C. G. Van de Walle, Phys. Rev. Lett. 85, 1012 (2000); C. G. Van de Walle, Physica B 308, 899 (2001); C. G. Van de Walle, Phys. Status Solidi B 229, 221 (2002). 